\title{
Nanoscale
}

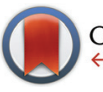

CrossMark

\& click for updates

Cite this: Nanoscale, 2015, 7, 11310

\section{Large-scale preparation of graphene by high temperature insertion of hydrogen into graphite $\uparrow$}

\begin{abstract}
Ali Reza Kamali* and Derek J. Fray
Experimental evidence for high temperature diffusion of hydrogen into the interlayer space of graphite is provided. This process is discussed as a possible method for the rapid production of high-quality, inexpensive graphene in large quantities, which could lead to the widespread application of graphene. It was found that hydrogen cations, dissolved in molten $\mathrm{LiCl}$, can be discharged on cathodically polarized graphite rods, which then intercalate into the graphite structure, leading to the peeling of graphite to produce graphene. The graphene nanosheets produced displayed a single-crystalline structure with a lateral size of several hundred nanometers and a high degree of crystallinity and thermal stability. The method introduced could be scaled up to produce industrial quantities of high-quality graphene.
\end{abstract}

Received 17th February 2015, Accepted 10th May 2015

DOI: $10.1039 / c 5 n r 01132 a$

www.rsc.org/nanoscale
Carbon nanostructures include fullerenes, carbon nanotubes, nanofibres and graphene. Particularly, graphene possesses many extraordinary properties such as high ballistic electron mobility, thermal conductivity, Young's modulus, fracture strength, and high specific surface area. ${ }^{12-16}$ Recently, graphene-based nanomaterials called carbon nanoflakes, ${ }^{17}$ nanoflowers, ${ }^{18}$ nanohorns, ${ }^{19}$ nanowalls $^{20}$ or graphene nanosheets ${ }^{21}$ have attracted extensive attention due to their unique dimensions, structure, and electronic properties which make them promising candidates for many applications such as electron field emitters, ${ }^{22}$ electrochemical capacitors, ${ }^{23}$ electrode material for capacitive deionisation, ${ }^{24}$ anode materials for lithium-ion batteries ${ }^{25,26}$ catalyst supports, ${ }^{27}$ biosensors,${ }^{28}$ electrodes for fuel cells, ${ }^{29}$ photocatalytic applications, ${ }^{30}$ nanocontactors $^{31}$ and field-effect transistors. ${ }^{32}$ Also, graphene nanosheets can be used as templates for the fabrication of other nanostructured materials. ${ }^{33}$

Graphene was initially produced in small amounts by the "up to bottom" approach of micromechanical cleavage of highly oriented pyrolytic graphite (HOPG) ${ }^{34}$ Then, relatively larger amounts of chemically modified graphene were produced by a number of methods. ${ }^{34-42}$ Many of these methods are based on chemical oxidization of graphite. The subsequent exfoliation of the graphite oxide formed leads to the formation of individual layers of graphene oxide, which are electrically insulating. Although graphene oxide sheets can be chemically reduced to remove most of the oxides, the reduction processes induce structural defects, resulting in deterioration of the product quality. ${ }^{42-45}$

In order to overcome this problem, non-chemical, solutionphase exfoliation of graphite in organic solvents has been investigated. ${ }^{46-49}$ However, these methods resulted in lowconcentration dispersions, which can be as low as $0.01 \mathrm{mg} \mathrm{ml}^{-1}{ }^{46}$ 
Unfortunately, water which is the most useful solvent cannot exfoliate graphene ${ }^{42}$ and all of these techniques make use of HOPG as the starting material and involve labour-intensive preparation.

Zhang et al. reported on the preparation of graphene flakes using carbonization and calcination of glucose and $\mathrm{FeCl}_{3}$ mixtures. $^{50}$ Although some success was achieved with this method, it was still a multi-step and time consuming process, and its scalability is yet to be evaluated.

Paton et al. ${ }^{51}$ reported the exfoliation of graphite powder to graphene flakes in solvents $N$-methyl-2-pyrrolidone, aqueous surfactant solution of sodium cholate, or polymer polyvinyl alcohol by the application of shear forces. In $\mathrm{N}$-methyl-2-pyrrolidone, graphene flakes of a mean thickness of about $7 \mathrm{~nm}$ with a yield of about $70 \%$ could be produced.

In an attempt towards the development of a green process avoiding the use of toxic organic solvents/surfactants, Liu et al. ${ }^{52}$ reported the exfoliation of graphite in a solution comprising of water, $\mathrm{FeCl}_{2}$ and sodium dodecylbenzenesulfonate with a weight ratio of $4: 300: 5: 2$, respectively, under the hydrothermal conditions of $240{ }^{\circ} \mathrm{C}, 3 \mathrm{MPa}$ and 4-10 h. Although single or fewlayered graphene could be produced, the yield of exfoliation was only $10 \%$, which could potentially be improved up to $35 \%$.

It should also be mentioned that horizontally ${ }^{53}$ or vertically $^{54}$ oriented graphene films can be grown on various substrates by chemical vapour deposition (CVD) techniques and also by pyrolysis-based methods. ${ }^{55,56}$ These techniques, however, have a number of drawbacks related to the low production rates which can be as low as $32 \mathrm{~nm} \min ^{-1},{ }^{57}$ low yields and the complexity of the equipment required.

As detailed above, the available methods of producing graphene suffer from one or more disadvantages such as a low rate of production, the low quality of graphene product and the use of hazardous organic solvents. Therefore, currently, there is no process available that can economically produce large amounts of graphene. Furthermore, alternative methods such as electrochemical exfoliation of graphite in ionic liquids ${ }^{58-61}$ require further investigation of their potential. Hence, the development of efficient production routes is considered a key element for widespread application of graphene. Here, for the first time, we report a unique process for rapid exfoliation of bulk graphite to graphene nanosheets based on high temperature intercalation of graphite with hydrogen in molten lithium chloride.

In the solid form, LiCl shows no considerable affinity for hydrolysis because of the energy barrier involved.

$$
\mathrm{LiCl}+\mathrm{H}_{2} \mathrm{O}(\mathrm{g})=\mathrm{LiOH}+\mathrm{HCl}(\mathrm{g}) \Delta G_{\left(T<600^{\circ} \mathrm{C}\right)}^{\circ}>78 \mathrm{~kJ}
$$

In the molten state, however, the hydrolysis of $\mathrm{LiCl}$ becomes much more significant because of the fact that the hydrolysis products are readily soluble in molten lithium chloride. At higher temperatures, the hydroxide can be transferred into oxide. ${ }^{62,63}$

The occurrence of the hydrolysis reaction leads to the formation of oxygen anions in the molten salt and hence is con- sidered to be undesirable in the electrochemical applications in which molten LiCl serves as the electrolyte such as the electrolytic production of lithium metal, ${ }^{64}$ the reprocessing of spent nuclear fuels, ${ }^{65}$ and thermal batteries. ${ }^{66,67}$

In this paper, however, the hydrolysis of molten $\mathrm{LiCl}$ is promoted in order to enhance the formation of hydrogen cations in the molten salt at $800{ }^{\circ} \mathrm{C}$. It is reported that the cathodic polarization of graphite electrodes exposed to the molten $\mathrm{LiCl}$ containing hydrogen cations leads to the exfoliation of the graphite cathodes into graphene nanosheets. This process offers a high production rate and product quality. Moreover, the process only uses industrial grade graphite, lithium chloride and water to produce graphene and lithium carbonate (as the by-product) and hence is environmentally acceptable. Lithium carbonate by-product could be removed from graphene nanosheets by a simple heat treatment.

\section{Results and discussion}

The structural and microstructural changes in an industrial synthetic graphite rod occurring by high temperature diffusion of hydrogen into its crystallites are investigated in this paper.

A schematic representation of the set-up used is shown in Fig. 1. A graphite rod was immersed in molten $\mathrm{LiCl}$ at $800{ }^{\circ} \mathrm{C}$ and cathodically polarized for $30 \mathrm{~min}$ at an electric current of 33 A in a moist Ar flow. The average potential difference between the graphite rod and a Mo pseudo-reference electrode immersed in molten LiCl was measured to be about $-2.8 \mathrm{~V}$ (Fig. 1S $\dagger$ ). After the molten salt process, the cell was cooled to room temperature. It was observed that the graphite rod served as the cathode was eroded and the erosion product is thoroughly mixed with the salt. Fig. 2 shows the photographs of the graphite rod which was used as the cathode in the molten salt process indicating considerable erosion of the graphite rod. A black powder (about $10 \mathrm{~g}$ ) was retrieved from the solidified salt mixture by washing with copious amounts of distilled water followed by vacuum filtering and drying at $150{ }^{\circ} \mathrm{C}$ for $2 \mathrm{~h}$. As discussed later in this article, the disintegration of the cathodically polarized graphite rod in molten $\mathrm{LiCl}$ under a moist atmosphere is attributed to the insertion of hydrogen into the crystalline lattice of the graphite material.

The structure and morphology of the as-received graphite material and the erosion product were characterized by various techniques. The X-ray diffraction pattern of the as-received graphite material used in the $2 \theta$ range from $20^{\circ}$ to $40^{\circ}$ is exhibited in Fig. 3a. The prominent and sharp peak in the profile at $2 \theta=26.441^{\circ}$ corresponds to the (002) peak of graphite with an interlayer distance of $0.337 \mathrm{~nm}$.

Fig. 4 shows the SEM morphology of the as-received graphite material. It consists of flake-like grains of different sizes ranging from 1 to $10 \mu \mathrm{m}$ with smooth or jagged edges. The grains, which are separated by submicrometer-sized voids, consist of graphite crystallites with an average height of $33.2 \mathrm{~nm}$, calculated from the XRD data of the (002) peak shown in Fig. 3 (see Table $1 \mathrm{~S} \dagger$ ). The as-received graphite is 


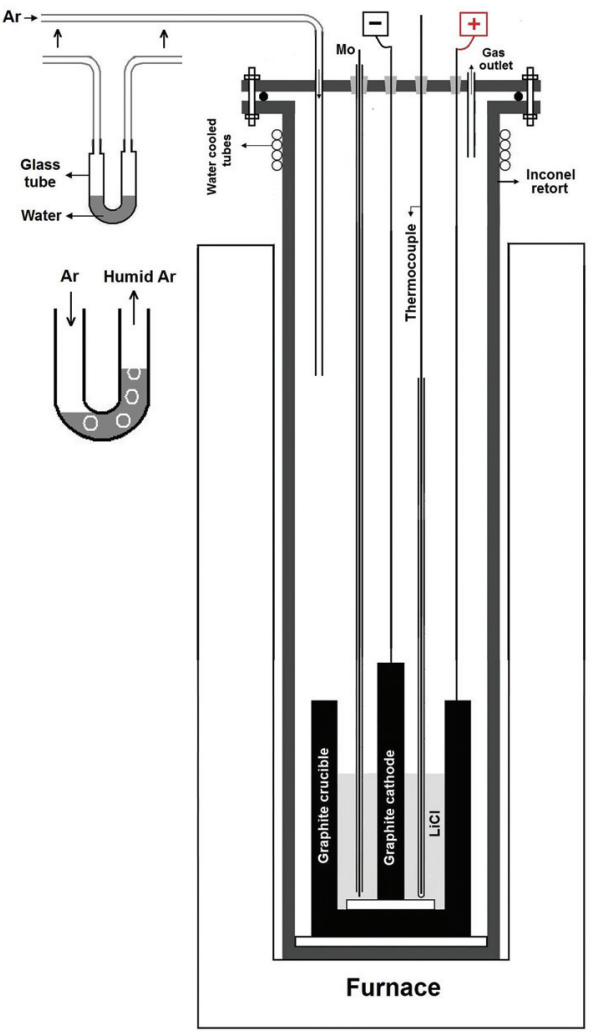

Fig. 1 A schematic presentation of the reactor used for the molten salt process. The apparatus comprised of a vertical tubular Inconel reactor, which is positioned inside a resistance furnace. The upper end of the reactor is closed with a stainless steel lid sealed with an O-ring and compression fittings. The lid is equipped with feedthroughs for electrodes leads and the thermocouple as well as with steel pipes for a gas inlet and an outlet. The gas inlet was coupled to a gas canister containing argon. The argon could bubble through the water within a U-bend tube before entering the reactor at the gas inlet. The U-bend tube is shown more clearly in the inset of the figure. On passing through the $\mathrm{U}$-bend tube, the dry argon absorbed the water vapour and becomes moist argon. Thus, the atmosphere within the reactor above the molten lithium chloride was moist argon that enters through the gas inlet and exits through the gas outlet.

prepared by mixing petroleum coke with a coal tar binder, followed by extrusion and baking to carbonize the binder. It was finally graphitized by heating at high temperatures, at which point the carbon atoms arrange into graphite. Owing to the manufacturing process, it contains porosity within its structure, as a consequence of mismatch between grains and gas evolution. The pore density in synthetic graphite materials can be as high as $10^{9}$ pores per $\mathrm{cm}^{3}$ with pore diameters varying between $1 \mathrm{~nm}$ and $1 \mathrm{~mm} .^{7,68}$

As explained above, a graphite rod of this material disintegrated during the molten salt process. Fig. $3 \mathrm{~b}$ shows the XRD profile of the carbonaceous materials obtained. The spectrum contains the (002) peak of graphite at $2 \theta=26.485^{\circ}$ corresponding to an interlayer distance of $0.336 \mathrm{~nm}$. It also contains additional peaks that are due to the $\mathrm{Li}_{2} \mathrm{CO}_{3}$ and $\mathrm{LiCl}$ phases. The results suggest that some quantity of lithium chloride can be trapped in the microstructure of the carbon materials pro-
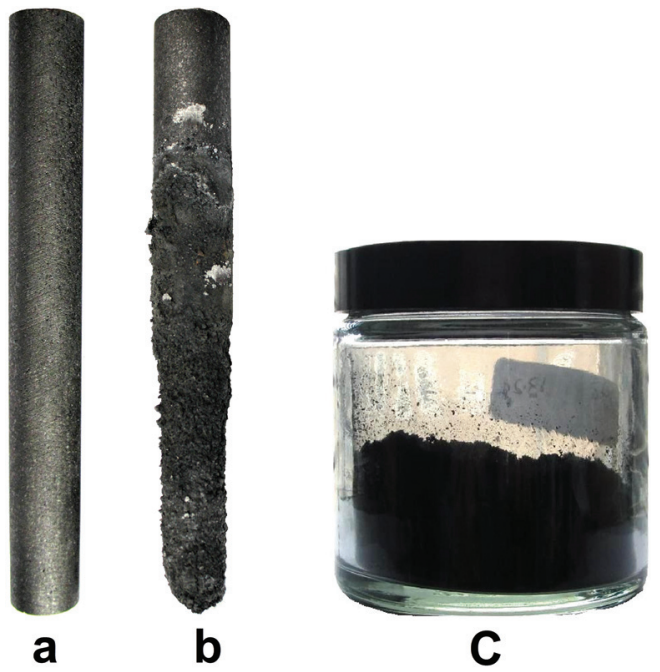

Fig. 2 The photographs of (a) the graphite rod which was used as the cathode in the molten salt process conducted under moist gas flow, (b) the graphite cathode after the molten salt process, and (c) the graphene product stored in a jar.

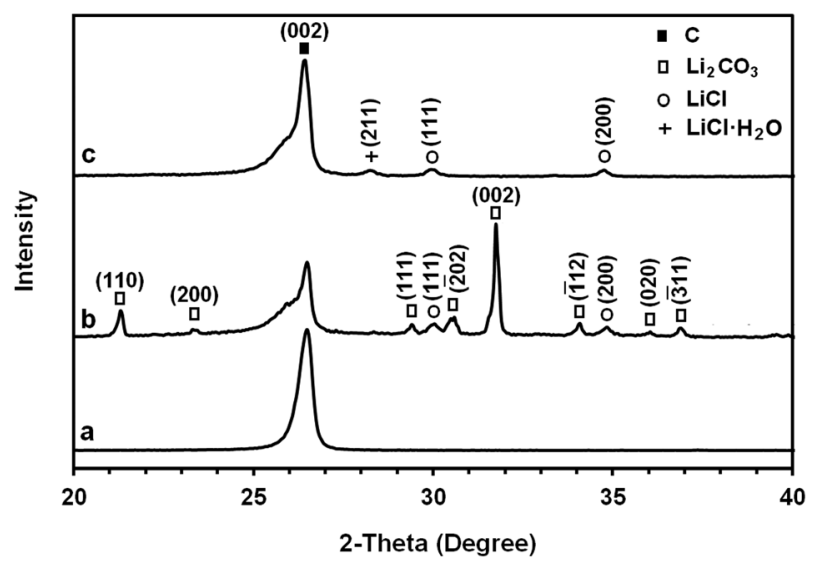

Fig. 3 The X-ray diffraction patterns of (a) the as-received graphite material used as the cathode during the molten salt process, (b) as-synthesised carbonaceous material and (c) graphene nanosheets produced by heating the as-synthesised carbonaceous material to $1300^{\circ} \mathrm{C}$.

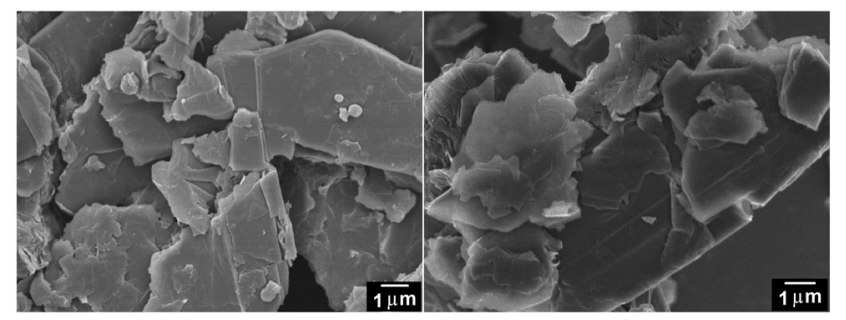

Fig. 4 SEM morphology of the as-received graphite material used as the cathode during the electrolysis process. 

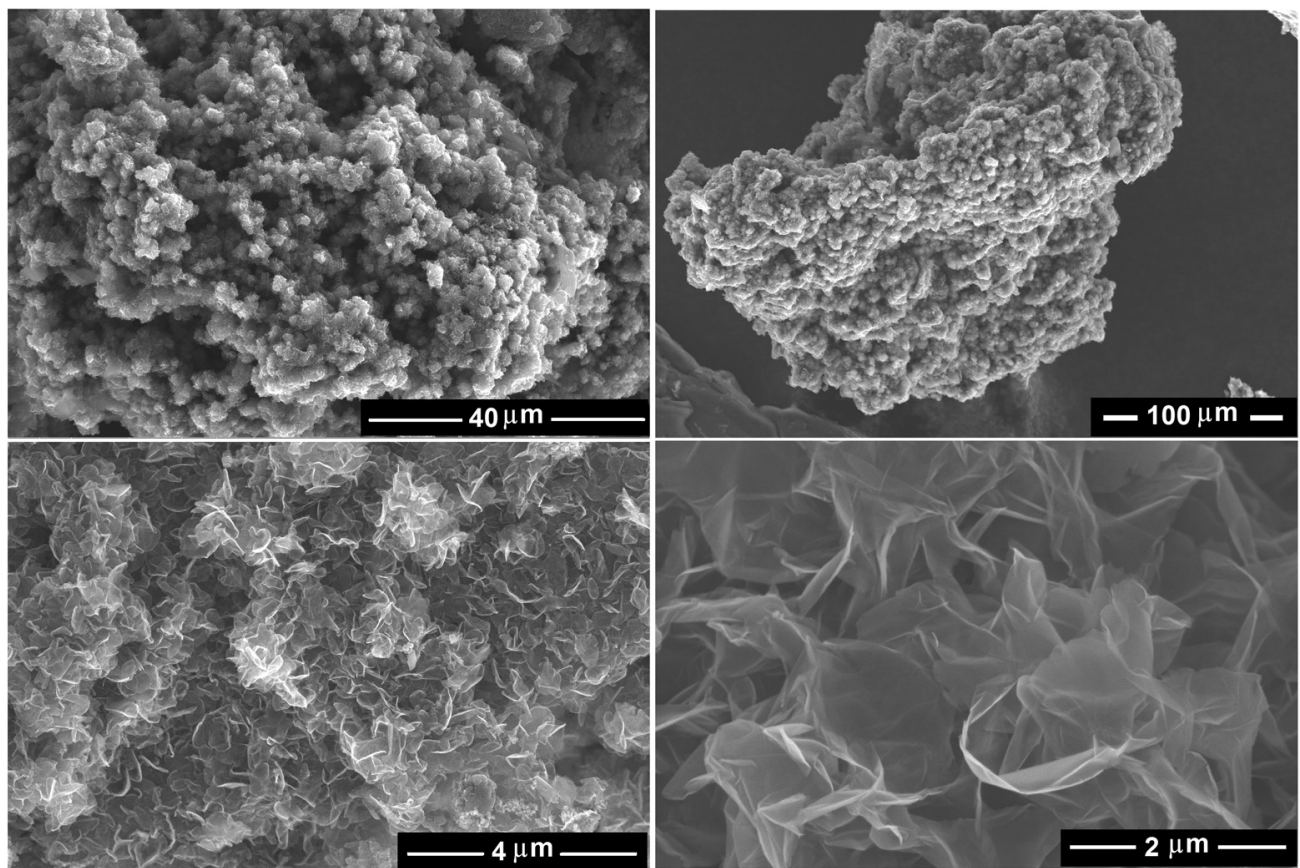

Fig. 5 Secondary electron SEM images of the graphene nanosheets, produced by heating the as-synthesised carbonaceous material to (left panels) $1300^{\circ} \mathrm{C}$ and (right-upper panel) $1450^{\circ} \mathrm{C}$ at different magnifications. The right-down panel shows a backscattered electron SEM micrograph of graphene nanosheets obtained at $1450^{\circ} \mathrm{C}$. The products exhibited nanosheets morphology with a high yield.

duced during the molten LiCl process. The trapped salt in the sample may not be removed completely by washing with water. The possible mechanism of the formation of $\mathrm{Li}_{2} \mathrm{CO}_{3}$ is discussed in this paper.

SEM studies (Fig. $2 \mathrm{~S}^{\dagger}$ ) have demonstrated that the as-synthesised carbonaceous material consisted of graphene nanosheets mixed with irregular structures originating from non-conductive $\mathrm{Li}_{2} \mathrm{CO}_{3}$ and $\mathrm{LiCl}$. The graphene nanosheets were separated from the lithium compounds by heating the assynthesised carbonaceous material.

It is worth noting that the large difference between the physical properties of carbon with the sublimation point of about $3640{ }^{\circ} \mathrm{C}$ and those of $\mathrm{Li}_{2} \mathrm{CO}_{3}$ and $\mathrm{LiCl}$ with the evaporation/decomposition point of about $1300^{\circ} \mathrm{C}$ makes it possible to reduce the amounts of $\mathrm{Li}_{2} \mathrm{CO}_{3}$ and $\mathrm{LiCl}$ in the as-synthesised carbonaceous material by an appropriate heat treatment. The heat treatment must be carried out in an atmosphere with a low oxygen concentration to avoid the high temperature oxidation of carbon. For this, the material was heated to $1300{ }^{\circ} \mathrm{C}$ with a dwell time of $30 \mathrm{~min}$ in a reducing atmosphere of $80 \% \mathrm{~N}_{2}-15 \% \mathrm{H}_{2}$. The XRD profile of the purified graphene nanosheets is shown in Fig. 3c. As it can be seen, the $\mathrm{Li}_{2} \mathrm{CO}_{3}$ diffraction peaks are absent from the XRD pattern, which indicates its removal during the heat treatment. However, as indicated in Fig. 3c, very weak diffraction peaks of $\mathrm{LiCl}$ and $\mathrm{LiCl} \cdot \mathrm{H}_{2} \mathrm{O}$ could still be detected in the pattern.

It is noteworthy that the SEM analysis of the heat-treated product, unlike that of the as-synthesised one, was possible without a need for coating with gold, demonstrating the removal of $\mathrm{Li}_{2} \mathrm{CO}_{3}$ and $\mathrm{LiCl}$ which acted as non-conductive impurities. The morphology of the material obtained is presented in the SEM micrographs shown in Fig. 5 (left panels), demonstrating the fabrication of high yield graphene nanosheets with the lateral size of several hundred nanometers. The upper panel in Fig. 6 shows a bright field TEM micrograph of the graphene nanosheets. The right-down panel of Fig. 6 exhibits a HRTEM image showing the presence of single-layered graphene sheets. A typical selected-area electron diffraction pattern taken from the edge of a nanosheet with the peaks labelled by Miller-Bravais indices can also be seen in Fig. 6 (left-down panel) revealing the distinctive hexagonal structure of graphene. The diffraction intensity ratio $I(1-210) / I(0-110)$ was analysed to be 0.8 indicating the presence of single-layered graphene. ${ }^{69}$ SEM and TEM images confirmed the preparation of high quality single- or few layered graphene.

Raman spectroscopy is a powerful technique to study the structural properties of carbon based materials. ${ }^{70}$ The raw Raman spectrum of the graphene nanosheets in the wavenumber range $200-3000 \mathrm{~cm}^{-1}$ is presented in Fig. $7 \mathrm{~b}$ (the upper panel). For comparison, the raw Raman spectrum of natural flake graphite is shown in Fig. 7a. Both spectra are characterized by the presence of the so-called $\mathrm{G}$ band at $1575-1581 \mathrm{~cm}^{-1}$ and the D band at $1327 \mathrm{~cm}^{-1}$. The G-band is related to the vibration of $\mathrm{sp}^{2}$ bonded carbon atoms in a twodimensional hexagonal lattice while the D-band is associated with structural defects and partially disordered carbon structures. The intensity ratio of the $\mathrm{G}$ and $\mathrm{D}$ bands, $I_{\mathrm{G}} / I_{\mathrm{D}}$, is an index corresponding to the crystallinity of graphitic carbons. 

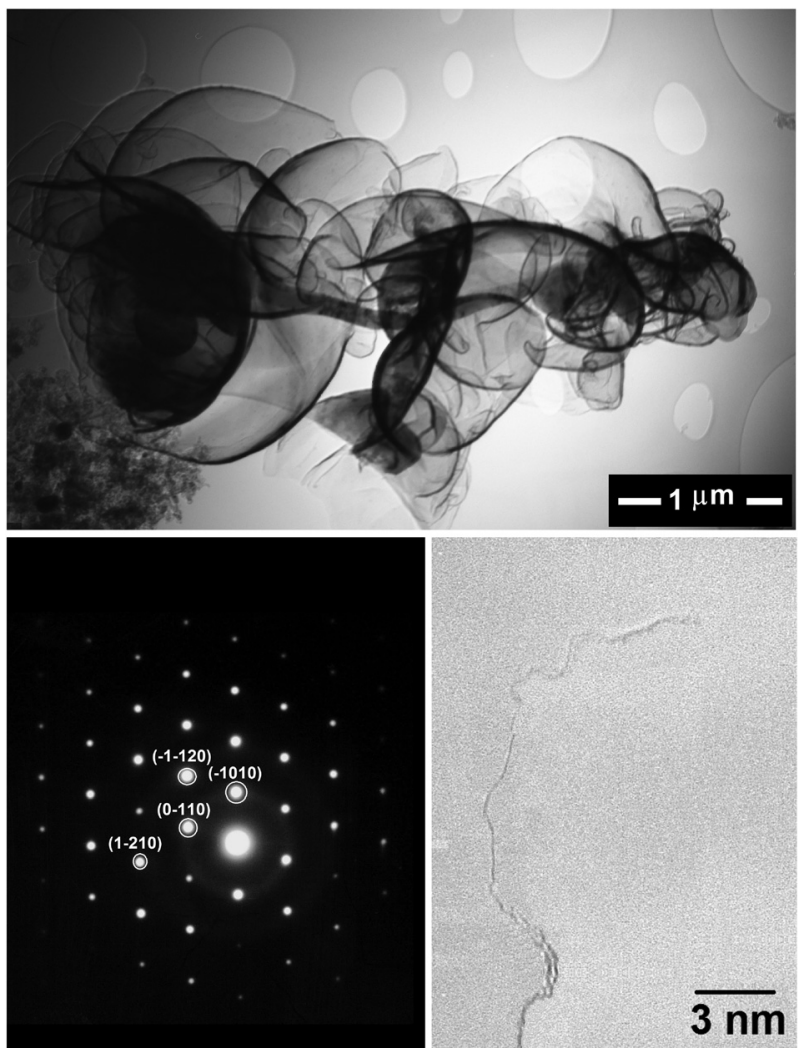

Fig. 6 The upper panel shows a TEM micrograph of the graphene nanosheets produced by heating the as-synthesised carbonaceous material to $1300{ }^{\circ} \mathrm{C}$. The left-down panel shows a typical electron diffraction pattern recorded at a relatively flat edge of a graphene sheet, with the peaks labelled by Miller-Bravais indices. The right-down panel exhibits a HRETM image showing a single-layer of graphene.

The $I_{\mathrm{G}} / I_{\mathrm{D}}$ ratio of the natural flake graphite and the graphene nanosheets were calculated from the Raman spectra, and these values were 8.8 and 3.5 , respectively. Taking into account that the $\mathrm{D}$ peak is also induced by the edge of the graphene sheets, the smaller value of the $I_{\mathrm{G}} / I_{\mathrm{D}}$ ratio in the graphene nanosheets, therefore, is attributed to their higher density of graphene edges. However, the $I_{\mathrm{G}} / I_{\mathrm{D}}$ ratio in the graphene nanosheets is still significantly high and suggests that the nanosheets produced are composed of carbon crystallites with a large degree of crystallinity. Cançado et $a .^{71}$ found that the average crystallite size $\left(L_{\mathrm{a}}\right)$ of graphene is proportional to $\left(I_{\mathrm{G}} / I_{\mathrm{D}}\right)$, and can be calculated as:

$$
L_{\mathrm{a}}(\mathrm{nm})=\left(\frac{I_{\mathrm{G}}}{I_{\mathrm{D}}}\right) \times\left(\frac{560}{E_{1}{ }^{4}}\right)
$$

where $E_{\mathrm{l}}$ is the excitation laser energy, given in $\mathrm{eV}$. The average crystallite size of graphene nanosheets obtained at $1300{ }^{\circ} \mathrm{C}$, therefore, is calculated to be $133 \mathrm{~nm}$.

The down panel of Fig. 7 shows the feature of $2 \mathrm{D}$ peaks at a higher resolution. It is known that the $2 \mathrm{D}$ peak of graphitic materials is extremely sensitive to the number of layers. The 2D peak of graphite is asymmetric consisting of two com-
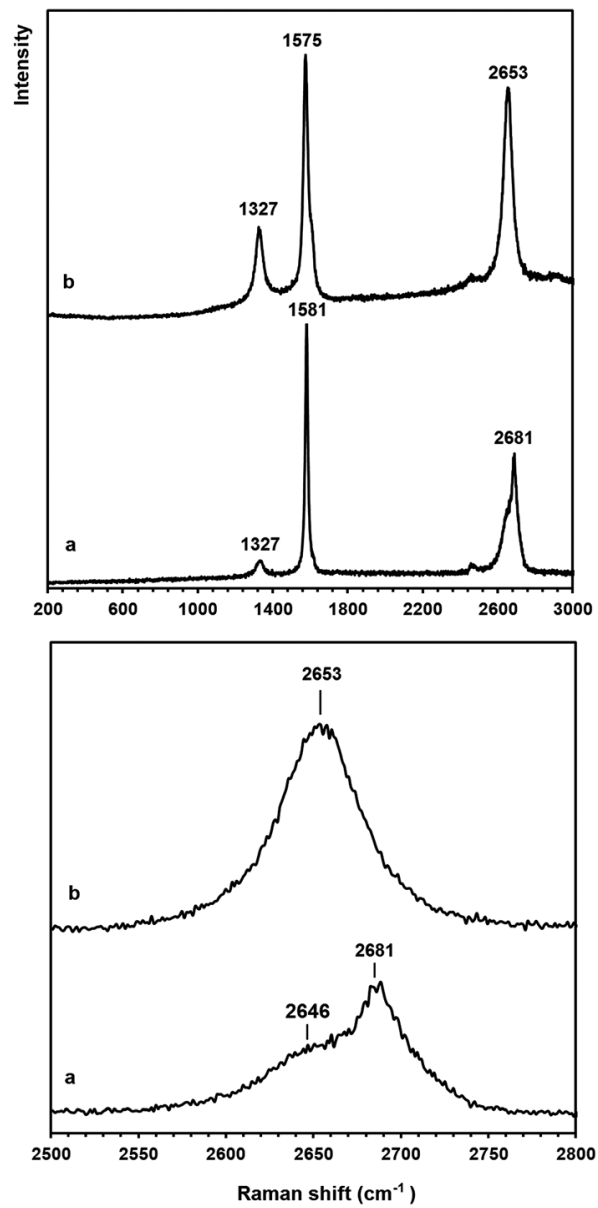

Fig. 7 Raman spectra of (a) natural graphite flakes and (b) graphene nanosheets which were produced in molten $\mathrm{LiCl}$, and then heated to $1300{ }^{\circ} \mathrm{C}$ in the range of (upper panel) 200-3000 and (down panel) $2500-2800 \mathrm{~cm}^{-1}$ at a $633 \mathrm{~nm}$ wavelength.

ponents of $2 \mathrm{D} 1$ and $2 \mathrm{D}_{2}$, whilst the $2 \mathrm{D}$ peak of single-layered graphene is composed of a single peak. ${ }^{72}$ The comparison of the shape of the $2 \mathrm{D}$ peak recorded on the natural graphite with that of the graphene nanosheets suggests that the graphene nanosheets produced have the Raman characteristics of single layered graphene. Thermal analysis studies (see Fig. $3 \mathrm{~S} \dagger$ ) confirmed that the graphene nanosheets prepared are thermally stable below $450{ }^{\circ} \mathrm{C}$.

It should be noted that the graphene nanosheets which were synthesised by heating the as-synthesised carbonaceous material to $1300{ }^{\circ} \mathrm{C}$ contained a small amount of lithium chloride, as shown in Fig. 3c. The residual lithium chloride in the graphene product could be eliminated by heating the assynthesised carbonaceous material to a higher temperature of $1450{ }^{\circ} \mathrm{C}$ in an atmosphere of Ar containing $4 \% \mathrm{H}_{2}$, as shown in Fig. 8 (upper panel). The Raman spectrum of the sample is displayed in Fig. 8 (down panel), from which the ratio of $I_{\mathrm{G}} / I_{\mathrm{D}}$ was determined to be 3.4. From this, the value of $L_{\mathrm{a}}$ was calculated, according to eqn (1), to be $129 \mathrm{~nm}$. A comparison of Fig. 3 and 8 indicates that increasing the heat treatment temp- 

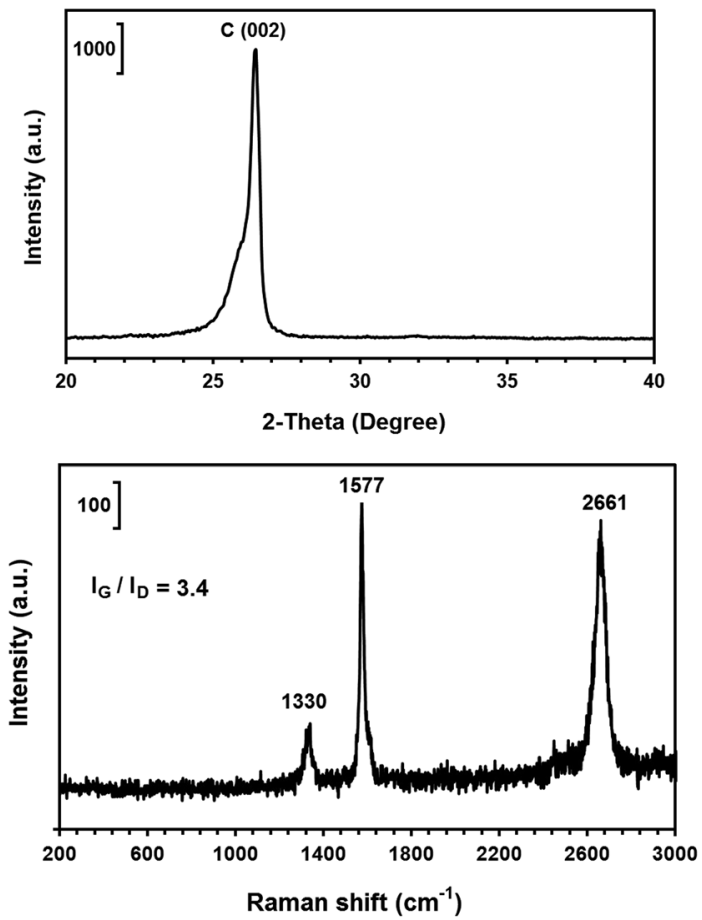

Fig. 8 The X-ray diffraction pattern (upper panel) and Raman spectra (down panel) of the graphene nanosheets produced by heating the assynthesised carbonaceous material to $1450^{\circ} \mathrm{C}$.

erature from 1300 to $1450{ }^{\circ} \mathrm{C}$ led to the elimination of the residual $\mathrm{LiCl}$, but did not change the average crystallite size of the graphene nanosheets. It confirms that the residual $\mathrm{LiCl}$ in graphene nanosheets did not contribute to the structural defects of the nanosheets.

It is worth noting that under ambient conditions, a low concentration of oxygen, as much as for example $3.56 \%{ }^{73}$ or $3.70 \%,{ }^{74}$ is always present in graphite in the form of oxygen molecules chemisorbed on the graphite edge planes and also oxygen atoms intercalated between basal planes. ${ }^{75}$

The $\mathrm{C} / \mathrm{O}$ atomic ratio of the as-received graphite material used as the cathode during the electrolysis process and graphene nanosheets was determined by elemental analysis and found to be 29.96 and 21.01, respectively. The higher C/O value in graphite in comparison with that of graphene is attributed to the higher edge density of graphene nanosheets. The BET specific surface area of the graphene sample obtained was measured by nitrogen adsorption and found to be $235 \mathrm{~m}^{2} \mathrm{~g}^{-1}$. Prior to the analysis, a sample of about $0.1 \mathrm{~g}$ was degassed at $300{ }^{\circ} \mathrm{C}$ under a vacuum of $10^{-3} \mathrm{~Pa}$ for $24 \mathrm{~h}$ in order to remove the adsorbed species.

Table 1 compares the properties of graphene nanosheets produced in this paper with selected graphene materials fabricated by other methods. From an application point of view, a graphene material with a higher degree of crystallinity and lower oxygen content is preferable as the structural defects and oxygen content of graphene have an adverse effect on the thermoelectric performance of graphene composites. ${ }^{103}$ It is also

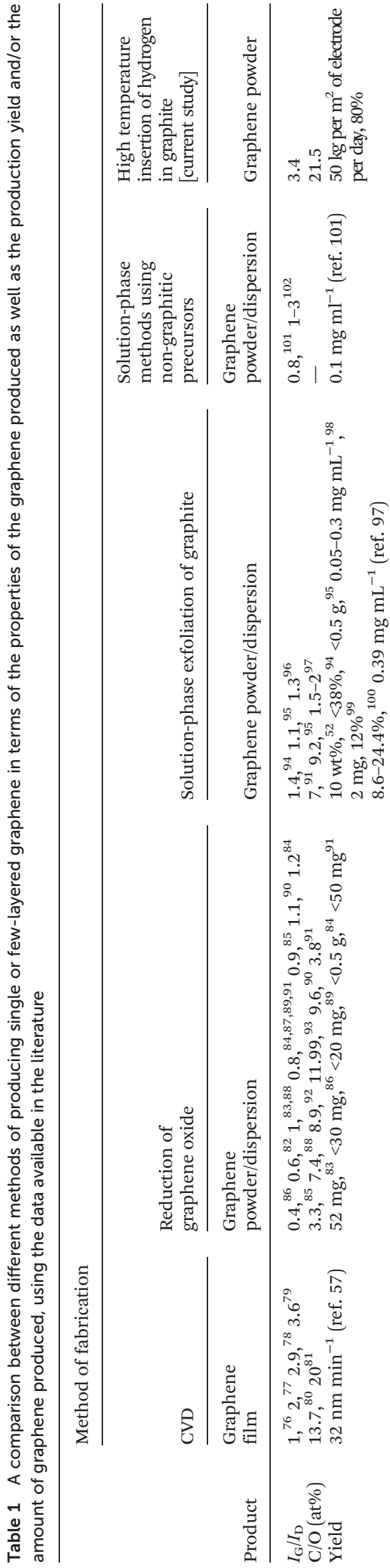


known that graphene with lower oxygen content shows lower hemolytic activity. ${ }^{97}$ The data displayed in Table 1 indicate that graphene nanosheets fabricated in this paper possess an interesting combination of high crystallinity and low oxygen content together with a high production rate.

Here we discuss the mechanisms involved in the formation of graphene nanosheets. It is known that molten $\mathrm{LiCl}^{63,105}$ and LiCl-based mixtures ${ }^{106-108}$ react under a humid atmosphere to form lithium oxide and hydrogen chloride according to reaction (1) with $\Delta G^{\circ}{ }_{800}^{\circ}{ }^{\circ}=85.3 \mathrm{~kJ}$.

Also it is known that the lithium hydroxide formed by the hydrolysis of $\mathrm{LiCl}$ can decompose to form lithium oxide, according to reaction (2). ${ }^{63}$

$$
2 \mathrm{LiOH}=\mathrm{Li}_{2} \mathrm{O}+\mathrm{H}_{2} \mathrm{O}(\mathrm{g}) \Delta G^{\circ} 800^{\circ} \mathrm{C}=11.3 \mathrm{~kJ}
$$

Although the Gibbs free energy of reactions (1) and (2) is positive, yet the reactions can proceed at a finite rate as a result of dissolution of products in the molten salt. It should be mentioned that lithium chloride is unique among the alkali chlorides in forming solid hydrates under ordinary conditions. Dehydration of lithium hydrates occurs at temperatures below $200{ }^{\circ} \mathrm{C}$ to form anhydrous lithium chloride. However, the tendency of $\mathrm{LiCl}$ to react with water (through hydrolysis) becomes more pronounced once the melting point has been exceeded, since both $\mathrm{LiOH}$ and $\mathrm{HCl}$ formed can dissolve in the molten $\mathrm{LiCl}^{63,108}$

$\mathrm{HCl}$ is soluble in LiCl-based molten salts and the dissolved $\mathrm{HCl}$ is dissociated into protons and chloride ions. The diffusion coefficient of the proton arising from the dissolved $\mathrm{HCl}$ is an order of magnitude higher than most other ions in molten salts. ${ }^{102-112}$ Also it is known that the solubility of $\mathrm{Li}_{2} \mathrm{O}$ in molten $\mathrm{LiCl}$ can be more than $11 \mathrm{~mol} \%{ }^{113}$

As a conclusion, reactions (1) and (2) lead to the formation of hydrogen cations $\left(\mathrm{H}^{+}\right)$and oxygen anions $\left(\mathrm{O}^{2-}\right)$ in molten LiCl. Therefore, the processes that occur during the cathodic polarization of the graphite rod in molten $\mathrm{LiCl}$ can be described as follow:

$$
\begin{gathered}
2 \mathrm{H}^{+}+2 \mathrm{e}=\mathrm{H}_{2}(\text { at the cathode }) \\
\mathrm{O}^{2-}+1 / 2 \mathrm{C}=1 / 2 \mathrm{CO}_{2}+2 \mathrm{e}(\text { at the anode })
\end{gathered}
$$

In fact, $\mathrm{H}_{2}$ (and no $\mathrm{Cl}_{2}$ ) could be detected in the gas stream outlet of the reactor shown in Fig. 1, confirming the occurrence of reaction (3). The structural disintegration of the graphite cathode to graphene sheets, therefore, can be attributed to the interaction of hydrogen formed with graphite. Hence, we should consider the hydrogen electrode reactions in more detail.

During cathodic polarisation, the reduction of proton from chloride molten salts on carbon cathodes is known to proceed via a reversible one electron charge transfer. ${ }^{109-112}$ Atomic hydrogen formed can be chemisorbed on the surface of graphite by binding to a carbon atom, leading to the formation of an additional $\sigma$ bond and the rehybridization from $\mathrm{sp}^{2}$ to $\mathrm{sp}^{3} \cdot{ }^{114-119}$
Therefore, the first step of the cathodic reaction is the formation of adsorbed atomic hydrogen on graphite $\left(\mathrm{H}_{\mathrm{ad}}\right)$ :

$$
\mathrm{H}^{+}+\mathrm{e} \rightarrow \mathrm{H}_{\mathrm{ad}}
$$

The subsequent step is the formation of molecular hydrogen: ${ }^{112-125}$

$$
\mathrm{H}_{\mathrm{ad}}+\mathrm{H}^{+}+\mathrm{e} \rightarrow \mathrm{H}_{2}
$$

Diffusion of atomic and molecular hydrogen in graphite has been theoretically studied. It was found that the diffusion of the chemisorbed hydrogen atoms on the surface of graphite crystallites is rather short and direct, ${ }^{11}$ and involves the breaking of the $\mathrm{C}-\mathrm{H}$ bond and forming another bond with a nearby carbon atom in the same or in an adjacent sheet, which requires an activation energy of $0.38-0.5 \mathrm{eV} .^{9,11,116}$

The temperature dependency of diffusion coefficient of atomic hydrogen on graphite sheets $\left(D_{\mathrm{H}}, \mathrm{cm}^{2} \mathrm{~s}^{-1}\right)$ can be concluded from ref. 11 to be:

$$
D_{\mathrm{H}}=2.0 \times 10^{-3} \exp \left(-6.09 \times 10^{-20} / k_{\mathrm{B}} T\right)\left(300-1700{ }^{\circ} \mathrm{C}\right)
$$

where $k_{\mathrm{B}}$ is the Boltzmann constant $\left(1.38 \times 10^{-23} \mathrm{~J} \mathrm{~K}^{-1}\right)$ and $T$ is the temperature (K). According to (7), at $25^{\circ} \mathrm{C}$ and $800{ }^{\circ} \mathrm{C}$, $D_{\mathrm{H}}$ has the values of $9.2 \times 10^{-10}$ and $3.3 \times 10^{-5} \mathrm{~cm}^{2} \mathrm{~s}^{-1}$, respectively, demonstrating a five order of magnitude difference in $H_{\text {ad }}$ diffusion speed.

The hydrogen atoms can then diffuse in the bulk of graphite through its porosity. ${ }^{7}$ In the as-received graphite electrode material, the graphite flakes are separated by micrometer sized-voids. Moreover, it is known that in a graphite flake, crystallites are usually separated by nanometre sized-voids which are a few $\AA$ in size, providing chemically reacting internal surfaces on which hydrogen atoms can diffuse and combine to form hydrogen molecules in the bulk of the graphite. ${ }^{7}$ The penetration of atomic hydrogen in graphite porosity is strongly affected by temperature and the hydrogen exposure rate. The typical time taken for hydrogen atoms to penetrate several $\AA$ into graphite is found to be about 15 days at $25^{\circ} \mathrm{C}$, less than a millisecond at $600{ }^{\circ} \mathrm{C}$ and around a microsecond at $1200{ }^{\circ} \mathrm{C} .{ }^{7}$ Causey et al. reported that when graphite is exposed to hydrogen atoms or ions, the retention of hydrogen considerably rises as the exposure rate exceeds $5 \times 10^{20}$ atoms per $\mathrm{cm}^{2}$, which is attributed to the fact that a greater number of atoms reach the internal porosity. ${ }^{68}$

In our experiments, the molten salt process was conducted at $800{ }^{\circ} \mathrm{C}$ and a current of $33 \mathrm{~A}$, corresponding to the cathode current density of about $1 \mathrm{~A} \mathrm{~cm}^{-2}$. It was found that graphite cathodes are visually eroded in molten LiCl under a humid $\mathrm{Ar}$ atmosphere if the cathode current density exceeds about $0.5 \mathrm{~A}$ $\mathrm{cm}^{-2}$, and that the rate of erosion increases with the current density. It is, therefore, straightforward to assume that more $H_{\text {ad }}$ (formed on the graphite cathode according to reaction (5)) can penetrate deep into the porosity of graphite material at higher current densities.

Under these conditions, the combination of hydrogen atoms to form hydrogen molecules (reaction (6)) is also likely 
to occur in the porosity of graphite. Therefore, the molecules formed have a reduced chance of escaping from the graphite electrode, and thus progressively dissolve in graphite.

Theoretical calculations show that $\mathrm{H}_{2}$ with a size of $2.5 \AA$ can diffuse in the interlayer space of graphite faster than atomic hydrogen. ${ }^{10,11,115,116}$ The energy activation for diffusion of atomic hydrogen in the interlayer space between graphene sheets in the hexagonal structure of graphite can be calculated to be very high ( $5 \mathrm{eV}$ ) owing to its ability to bind to carbon atoms, and therefore, the likelihood of hydrogen intercalation in graphite is low. ${ }^{11}$

There is no direct bonding between molecular hydrogen and graphite. The diffusion coefficient of molecular hydrogen in graphite does not follow a single straight Arrhenius line (such as eqn (7)). At room temperature, the molecular diffusion proceeds via jumps between the nearest-neighbour adsorption sites in a random walk of the $\mathrm{H}_{2}$ molecule in the interlayer space. At temperatures greater than about $200{ }^{\circ} \mathrm{C}$, however, the hydrogen molecules jump about twice longer and also mostly one-directional, enhancing the effective diffusion length of $\mathrm{H}_{2}$ in graphite. ${ }^{11}$ At 25 and $800{ }^{\circ} \mathrm{C}$, the diffusion coefficient of $\mathrm{H}_{2}$ in the interlayer space of graphite $\left(D_{\mathrm{H}_{2}}\right)$ can be extracted from ref. 11 to have the values of $6.9 \times 10^{-6}$ and $3.5 \times 10^{-4} \mathrm{~cm}^{2} \mathrm{~s}^{-1}$, respectively. The activation energy of the later was calculated to be only $0.19 \mathrm{eV} .^{11}$

The thermal behaviour of hydrogen between graphite layers has been addressed in a number of studies. ${ }^{8,9,11}$ Moleculardynamics simulations have shown that the kinetic energy of a $\mathrm{H}_{2}$ molecule in the interlayer space of graphite increases as the temperature rises, so that it was calculated to be 22.9 and $32.7 \mathrm{~kJ} \mathrm{~mol}^{-1}$ at 25 and about $800{ }^{\circ} \mathrm{C}$, respectively. ${ }^{11}$

The interlayer binding energy of highly oriented pyrolytic graphite was measured to be about $0.19 \mathrm{~J} \mathrm{~m}^{-2}$. However, the exfoliation energy, the energy required to remove one graphene layer from single-crystalline graphite, was experimentally measured and the values reported were $0.26^{126}$ and $0.32 \mathrm{~J}$ $\mathrm{m}^{-2} \cdot{ }^{127}$ The exfoliation energy was also theoretically calculated to be $0.31 \mathrm{~J} \mathrm{~m}^{-2}$. 128

Considering the density and the interlayer space of the asreceived graphite to be $2.7 \mathrm{~g} \mathrm{~cm}^{-3}$ and $0.337 \mathrm{~nm}$, respectively, and using the above values, it can be concluded that a local concentration of more than $2 \mathrm{wt} \% \mathrm{H}_{2}$ in graphite is energetically enough to exfoliate graphite into graphene, and thus to the surface erosion of the graphite cathode. Exceeding this critical concentration should be possible during the cathodic polarization of the graphite electrode, considering the fact that the interlayer space in graphite can theoretically accommodate hydrogen molecules up to $6 \mathrm{wt} \%{ }^{129}$ A higher hydrogen concentration of $7.4 \mathrm{wt} \%$ has also been reported in some specific conditions. ${ }^{130}$ Giving these figures, the exfoliation of graphite cathodes in our experiment can be attributed to the diffusion of hydrogen into the interlayer space of graphite.

According to Fig. 3b, the as-synthesized carbonaceous material contained $\mathrm{Li}_{2} \mathrm{CO}_{3}$. The formation of lithium carbonate during the molten salt process can be attributed to the reaction between $\mathrm{CO}_{2}$ formed at the anode (reaction (4)) and the $\mathrm{Li}_{2} \mathrm{O}$ dissolved in the molten salt (formed by reaction (2)):

$$
\mathrm{CO}_{2}+\mathrm{Li}_{2} \mathrm{O}=\mathrm{Li}_{2} \mathrm{CO}_{3} \Delta G^{\circ}{ }_{800}{ }^{\circ} \mathrm{C}=-66.0 \mathrm{~kJ}
$$

As explained, $\mathrm{Li}_{2} \mathrm{CO}_{3}$ can be removed from the graphene product by an appropriate heat treatment.

This paper provides insights into the feasibility of large scale preparation of inexpensive but high quality graphene nanosheets by a simple molten salt method, exhibiting at least a 10-fold higher production rate in comparison with that of the currently available methods, such as CVD and wet chemistry techniques. Moreover, industrial grade graphite electrodes which could be used as the raw material for the preparation of graphene by this method are readily available on a large scale with reasonably low costs. Such electrodes are primarily used as the electrodes of electric arc and ladle furnaces in the steel industry and therefore are readily available in different sizes up to about $3 \mathrm{~m}$ long and $0.7 \mathrm{~m}$ in diameter. The graphene production rate by this method is more than $50 \mathrm{~kg}$ per $\mathrm{m}^{2}$ of electrode per day.

\section{Conclusions}

The application of a cathodic potential to graphite electrodes immersed in molten $\mathrm{LiCl}$ in a moist argon gas flow leads to the formation of a high yield of graphene nanosheets mixed with lithium carbonate. The $\mathrm{Li}_{2} \mathrm{CO}_{3}$ was then removed by heating the product at a high temperature, leaving graphene nanosheets. The formation of high quality graphene produced was attributed to the intercalation of hydrogen into the interlayer space of graphite crystallites at the graphite electrode. The graphene nanosheets produced possessed a lateral size of several hundred nanometers and a hexagonal structure of graphene. The process proposed is anticipated to be a simple and efficient method for the large-scale production of graphene nanomaterials.

\section{Experimental}

\section{Preparation of graphene nanosheets}

Anhydrous lithium chloride powder (Sigma Aldrich), 250 g, was placed in a graphite crucible with an internal diameter of $60 \mathrm{~mm}$ and a height of $150 \mathrm{~mm}$. The graphite crucible and a graphite rod (Morgan Advanced Materials, industrial grade synthetic graphite) with a diameter of $15 \mathrm{~mm}$ and a length of $120 \mathrm{~mm}$ were employed as the anode and the cathode, respectively, during the electrochemical process. The temperature was measured by the thermocouple placed inside the graphite crucible. At first, the temperature was raised to about $800{ }^{\circ} \mathrm{C}$, above the melting point of $\mathrm{LiCl}$, by a ramp of $5{ }^{\circ} \mathrm{C} \mathrm{min}^{-1}$, under an argon flow of $20 \mathrm{~cm}^{3} \mathrm{~min}^{-1}$. At this temperature, a water bath was placed in the path of the argon gas and the flow of the gas was set at $100 \mathrm{~cm}^{3} \mathrm{~min}^{-1}$ (see Fig. 1). Then a constant direct current of 33.0 A was applied between the cathode and the anode for about $30 \mathrm{~min}$. 
The potential difference between both the graphite electrodes and a Mo pseudo-reference electrode immersed in molten $\mathrm{LiCl}$ was measured during the electrochemical process. After the molten salt process, the cell was cooled to room temperature, and the product obtained retrieved from the solidified salt by washing with copious amounts of distilled water and vacuum filtering. A black powder was obtained and dried at $150{ }^{\circ} \mathrm{C}$ for $2 \mathrm{~h}$. In the second step, the dried material (about $10 \mathrm{~g}$ ) was heat treated in a horizontal tube furnace under the atmosphere of an inert gas containing hydrogen. The tube furnace was equipped with a thermocouple as well as hydrogen detection and fire detection systems. For this, the temperature was raised to 1300 or $1450{ }^{\circ} \mathrm{C}$ at a heating rate of $15^{\circ} \mathrm{C} \mathrm{min} \mathrm{m}^{-1}$ and held at this temperature for $30 \mathrm{~min}$, before cooling down to room temperature. The final product (about $6 \mathrm{~g}$ ) was a black fluffy powder which was characterized to be graphene nanosheets.

\section{Characterization methods}

A JEOL 6340F field emission scanning electron microscope (SEM), a $200 \mathrm{kV}$ JEOL 2000FX analytical transmission electron microscope (TEM) equipped with electron diffraction, and a 200 kV FEI Tecnai F20 field emission gun high resolution TEM (HRTEM) were used for electron microscopy evaluations. A Philips $1710 \mathrm{X}$-ray diffractometer (XRD) with $\mathrm{Cu}-\mathrm{K} \alpha$ radiation $\left(k=1.54 \mathrm{~A}^{\circ}\right)$ was used to record the diffraction patterns with a step size and a dwell time of $0.052 \theta$ and $5 \mathrm{~s}$, respectively. The diffraction patterns recorded were analyzed using the X'Pert High Score Plus program. Raman data were collected using a Renishaw 1000 Ramanscope with a He-Ne ion laser of a wavelength of $633 \mathrm{~nm}$ (red, $1.96 \mathrm{eV}$ ). The thermal analysis study including thermal gravimetry (TG) and differential scanning calorimetry (DSC) was carried out with $3.3 \mathrm{mg}$ of the as-synthesized carbonaceous material, $3.3 \mathrm{mg}$ graphene nanosheets and $10 \mathrm{mg}$ as-received graphite powder using a thermal analyser model SDT-Q600 equipped with alumina crucibles. The difference in the mass of the materials used was due to the fluffy nature of carbon nanomaterials in comparison with the graphite powder. The thermal analysis was conducted at a heating rate of $40{ }^{\circ} \mathrm{C} \mathrm{min}^{-1}$ under a constant air flow rate of

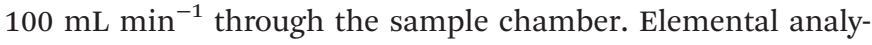
sis was carried out using a CHN/O Analyzer, Model PerkinElmer 2400. Brunauer-Emmett-Teller (BET) surface area analysis was performed by recording nitrogen adsorption/desorption isotherms using a static volumetric technique with a Micromeritics TriStar 3000 V6.04 A analyser at $-196{ }^{\circ} \mathrm{C}$.

\section{Notes and references}

1 S. Konstantinos, D. Gournis and P. Rudolf, ECS J. Solid State Sci. Technol., 2013, 2, M3160.

2 S. L. Kanashenko, A. E. Gorodetsky, V. N. Chemikov, A. V. Markin, A. P. Zakharov, B. L. Doyle and W. R. Wampler, J. Nucl. Mater., 1996, 233-237, 1207.
3 J. Greeley, T. F. Jaramillo, J. Bonde, I. B. Chorkendorff and J. K. Norskov, Computational high-throughput screening of electrocatalyticmaterials for hydrogen evolution, Nat. Mater., 2006, 5, 909.

4 V. L. Page, T. P. Snow and V. M. Bierbaum, Astrophys. J., 2009, 704, 274.

5 O. E. Haas, J. M. Simon and S. Kjelstrup, J. Phys. Chem. C, 2009, 113, 20281.

6 D. C. Elias, R. R. Nair, T. M. G. Mohiuddin, S. V. Morozov, P. Blake, M. P. Halsall, A. C. Ferrari, D. W. Boukhvalov, M. I. Katsnelson, A. K. Geim and K. S. Novoselov, Science, 2009, 323, 610.

7 M. Warrier, R. Schneider, E. Salonen and K. Nordlund, Nucl. Fusion, 2007, 47, 1656.

8 M. Warrier, R. Schneider, E. Salonen and K. Nordlund, Phys. Scr., 2004, T108, 85.

9 A. Shimizu and H. Tachikawa, J. Phys. Chem. Solids, 2003, 64, 419.

10 H. Atsumi, J. Nucl. Mater., 2002, 307-311, 1466.

11 C. P. Herrero and R. Ramirez, J. Phys. D: Appl. Phys., 2010, 43, 255402.

12 X. Li, W. Cai, J. An, S. Kim, J. Nah, D. Yang, R. Piner, A. Velamakanni, I. Jung, E. Tutuc, S. K. Banerjee, L. Colombo and R. S. Ruoff, Science, 2009, 324, 1312.

13 C. Berger, Z. Song, X. Li, X. Wu, N. Brown, C. Naud, D. Mayou, T. Li, J. Hass, A. N. Marchenkov, E. H. Conrad, P. N. First and W. A. de Heer, Science, 2006, 312, 1191.

14 X. Li, Y. Zhu, W. Cai, M. Borysiak, B. Han, D. Chen, R. D. Piner, L. Colombo and R. S. Ruoff, Nano Lett., 2009, 9, 4359.

15 W. Cai, Y. Zhu, X. Li, R. D. Piner and R. S. Ruoff, Appl. Phys. Lett., 2009, 95, 123115.

16 M. D. Stoller, S. Park, Y. Zhu, J. An and R. S. Ruoff, Nano Lett., 2008, 8, 3498.

17 Y. NuLi, P. Zhang, Z. Guo, H. Liu, J. Yang and J. J. Wang, J. Mater. Res. Bull, 2009, 44, 140.

18 X. Ma and B. Yuan, Appl. Surf. Sci., 2009, 255, 7846.

19 B. Aïssa, Z. Hamoudi, H. Takahashi, K. Tohji, M. Mohamedi and M. A. E. Khakani, Electrochem. Commun., 2009, 11, 862.

20 S. Shimada, K. Teii and M. Nakashima, Diam. Relat. Mater., 2010, 19, 956.

21 Q. Kuang, S. Y. Xie, Z. Y. Jiang, X. H. Zhang, Z. X. Xie, R. B. Huang and L. S. Zheng, Carbon, 2004, 42, 1737.

22 M. Y. Zhu, R. A. Outlaw, M. Bagge-Hansen, H. J. Chen and D. M. Manos, Carbon, 2011, 49, 2526.

23 L. Hou, L. Lian, D. Li, G. Pang, J. Li, X. Zhang, S. Xiong and C. Yuan, Carbon, 2013, 64, 149.

24 B. Jia and L. Zou, Carbon, 2012, 50, 2315.

25 A. R. Kamali and D. J. Fray, J. New Mater. Electrochem. Syst., 2010, 13, 147.

26 G. Wang, X. Shen, J. Yao and J. Park, Carbon, 2009, 47, 2049.

27 S. Yang, C. Shen, X. Lu, H. Tong, J. Zhu, X. Zhang and H. J. Gao, Electrochim. Acta, 2012, 62, 242.

28 Z. Wang, M. Shoji and H. Ogata, Talanta, 2012, 99, 487. 
29 Z. Wang, M. Shoji and H. Ogata, Appl. Surf. Sci., 2012, 259, 219.

30 S. Ghasemi, S. R. Setayesh, A. Habibi-Yangjeh, M. R. Hormozi-Nezhad and M. R. Gholami, J. Hazard. Mater., 2012, 199-200, 170.

31 C. Zhang, Y. Wang and L. Huang, Appl. Phys. Lett., 2010, 97, 062102.

32 Q. He, S. Wu, Z. Yin and H. Zhang, Chem. Sci., 2012, 3, 1764.

33 H. Wanga, Y. Su, S. Chen and X. Quan, Mater. Res. Bull., 2013, 48, 1304.

34 K. S. Novoselov, D. Jiang, F. Schedin, T. J. Booth, V. V. Khotkevich, S. V. Morozov and A. K. Geim, Proc. Natl. Acad. Sci. U. S. A., 2005, 102, 10451.

35 X. Li, X. Wang, L. Zhang, S. Lee and H. Dai, Science, 2008, 319, 1229.

36 C. Berger, Z. Song, T. Li, X. Li, A. Y. Ogbazghi, R. Feng, Z. Dai, A. N. Marchenkov, E. H. Conrad, P. N. First and W. A. de Heer, J. Phys. Chem. B, 2004, 108, 19912.

37 B. Puangbuppha, P. Limsuwan and P. Asanithi, Procedia Eng., 2012, 32, 1094.

38 D. Li, M. Muller, S. Gilje, R. Kaner and G. Wallace, Nat. Nanotechnol., 2008, 3, 101.

39 S. Niyogi, E. Bekyarova, M. E. Itkis, J. L. McWilliams, M. A. Hamon and R. C. Haddon, J. Am. Chem. Soc., 2006, 128, 7720.

40 S. Gilje, S. Han, M. Wang, K. Wang and R. Kaner, Nano Lett., 2007, 7, 3394.

41 G. Compagnini, M. Sinatra, P. Russo, G. C. Messina, O. Puglisi and S. Scalese, Carbon, 2012, 50, 2347.

42 V. Nicolosi, M. Chhowalla, M. G. Kanatzidis, M. S. Strano and J. N. Coleman, Science, 2013, 340, 1226419.

43 D. R. Dreyer, S. Park, C. W. Bielawski and R. S. Ruoff, Chem. Soc. Rev., 2010, 39, 228.

44 Y. Hong, Z. Wang and X. Jin, Sci. Rep., 2013, 3, 3439. 45 J. Chen, B. Yao, C. Li and G. Shi, Carbon, 2013, 64, 225. 46 Y. Hernandez, V. Nicolosi, M. Lotya, F. M. Blighe, Z. Sun, S. De, I. T. McGovern, B. Holland, M. Byrne, Y. K. GunKo, J. J. Boland, P. Niraj, G. Duesberg, S. Krishnamurthy, R. Goodhue, J. Hutchison, V. O. Scardaci, A. C. Ferrari and J. N. Coleman, Nat. Nanotechnol., 2008, 3, 563.

47 J. S. Bunch, Y. Yaish, M. Brink, K. Bolotin and P. L. McEuen, Nano Lett., 2005, 5, 287.

48 P. Blake, P. D. Brimicombe, P. R. Nair, T. J. Booth, D. Jiang, F. Schedin, L. A. Ponomarenko, S. V. Morozov, H. F. Gleeson, E. W. Hill, A. K. Geim and K. S. Novoselov, Nano Lett., 2008, 8, 1704.

49 J. N. Coleman, Acc. Chem. Res., 2013, 46, 14.

50 B. Zhang, J. Song, G. Yang and B. Han, Chem. Sci., 2014, 5, 4656.

51 K. R. Paton, E. Varrla, C. Backes, R. J. Smith, U. Khan, A. O'Neill1, C. Boland, M. Lotya, O. M. Istrate, P. King, T. Higgins, S. Barwich, P. May, P. Puczkarski, I. Ahmed, M. Moebius, H. Pettersson, E. Long, J. Coelho, S. E. O'Brien, E. K. McGuire, B. M. Sanchez, G. S. Duesberg, N. McEvoy, T. J. Pennycook, C. Downing,
A. Crossley, V. Nicolosi and J. N. Coleman, Nat. Mater., 2014, 13, 624.

52 X. Liu, M. Zheng, K. Xiao, Y. Xiao, C. He, H. Dong, B. Lei and Y. Liu, Nanoscale, 2014, 6, 4598.

53 Y. Zhang, L. Zhang and C. Zhou, Acc. Chem. Res., 2013, 46, 2329.

54 Z. Bo, Y. Yang, J. Chen, K. Yu, J. Yan and K. Cen, Nanoscale, 2013, 5, 5180.

55 J. Zhang, I. Khatri, N. Kishi, S. M. Mominuzzaman, T. Soga and T. Jimbo, Thin Solid Films, 2011, 519, 4162.

56 M. Choucair, P. Thordarson and J. A. Stride, Nat. Nanotechnol., 2009, 4, 30.

57 T. Mori, M. Hiramatsu, K. Yamakawa, K. Takeda and M. Hori, Diam. Relat. Mater., 2008, 17, 1513.

58 J. Lu, J. X. Yang, J. Z. Wang, A. L. Lim, S. Wang and K. P. Loh, ACS Nano, 2009, 3, 2367.

59 G. X. Wang, B. Wang, J. Park, Y. Wang, B. Sun and J. Yao, Carbon, 2009, 47, 3242.

60 M. Mao, M. Wang, J. Hu, G. Lei, S. Chen and H. Liu, Chem. Commun., 2013, 49, 5301.

61 H. Huang, Y. Xia, X. Tao, J. Du, J. Fang, Y. Gan and W. Zhang, J. Mater. Chem., 2012, 22, 10452.

62 P. Masset, ECS Trans., 2010, 25, 155.

63 A. R. Kamali, D. J. Fray and C. Schwandt, J. Therm. Anal. Calorim., 2011, 104, 619.

64 O. Takeda, M. Li, T. Toma, K. Sugiyama, M. Hoshi and Y. Sato, J. Electrochem. Soc., 2014, 161, D820.

65 Y. Castrillejo, C. de la Fuente, M. Vega1, F. de la Rosa, R. Pardo and E. Barrado, Electrochim. Acta, 2013, 97, 120.

66 P. Masset and R. A. Guidotti, J. Power Sources, 2007, 164, 397.

67 P. Masset, J. Y. Poinso and J. C. Poignet, J. Power Sources, 2004, 137, 140.

68 R. A. Causey, J. Nucl. Mater., 1989, 162, 151.

69 C. Shih, A. Vijayaraghavan, R. Krishnan, R. Sharma, J. H. Han, M. H. Ham, Z. Jin, S. Lin, G. L. C. Paulus, N. F. Reuel, Q. H. Wang, D. Blankschtein and M. 1. S. Strano, Nat. Nanotechnol., 2011, 6, 439.

70 M. S. Dresselhaus, A. Jorio and R. Saito, Annu. Rev. Condens. Matter. Phys., 2010, 89, 108.

71 L. G. Cançado, K. Takai, T. Enoki, M. Endo, Y. A. Kim, H. Mizusaki, A. Jorio, L. N. Coelho, R. Magalhães-Paniago and M. A. Pimenta, Appl. Phys. Lett., 2006, 88, 163106.

72 A. C. Ferrari, Solid State Commun., 2007, 143, 47.

73 Y. Wen, K. He, Y. Zhu, F. Han, Y. Xu, I. Matsuda, Y. Ishii, J. Cumings and C. Wang, Nat. Commun., 2014, 5, 4033.

74 F. Wah Low, C. W. Lai and S. B. Abd Hamid, Ceram. Int., 2015, 41, 5798.

75 Z. Pan and R. T. Yang, Ind. Eng. Chem. Res., 1992, 31, 2675-2680.

76 X. Song, J. Liu, L. Yu, J. Yang, L. Fang, H. Shi, C. Du and D. Wei, Mater. Lett., 2014, 137, 25.

77 Y. Tzeng, W. L. Chen, C. Wu, J. Y. Lo and C. Y. Li, Carbon, 2013, 53, 120.

78 E. Dervishi, Z. Li, F. Watanabe, A. Biswas, Y. Xu, A. R. Biris, V. Saini and A. S. Biris, Chem. Commun., 2009, 4061. 
79 C. H. Tu, W. Chen, H. C. Fang, Y. Tzeng and C. P. Liu, Carbon, 2013, 54, 234.

80 D. A. C. Brownson, M. Gómez-Mingot and C. E. Banks, Phys. Chem. Chem. Phys., 2011, 13, 20284.

81 D. A. C. Brownson, S. A. Varey, F. Hussain, S. J. Haigh and C. E. Banks, Nanoscale, 2014, 6, 1607.

82 J. Chen, Y. Li, L. Huang, C. Li and G. Shi, Carbon, 2015, 81, 826.

83 F. T. Johra, J. W. Lee, W. G. Jung and F. Tuz, J. Ind. Eng. Chem., 2014, 20, 2883.

84 Z. Chen, T. Huang, B. C. Jin, J. Hu, H. Lu and S. Nutt, Carbon, 2014, 68, 167.

85 X. Mei, X. Meng and F. Wu, Physica E, 2015, 68, 81.

86 W. Yoon, Y. Lee, H. Jang, M. Jang, J. S. Kim, H. S. Lee, S. Im, D. W. Boo, J. Parkc and S. Y. Jua, Carbon, 2015, 81, 629.

87 Y. Zhang, H. L. Ma, Q. Zhang, J. Peng, J. Li, M. Zhai and Z. Z. Yu, J. Mater. Chem., 2012, 22, 13064.

88 B. Shen, D. Lu, W. Zhai and W. Zheng, J. Mater. Chem. C, 2013, 1, 50 .

89 S. Some, S. Kim, K. Samanta, Y. Kim, Y. Yoon, Y. Park, S. M. Lee, K. Lee and H. Lee, Nanoscale, 2014, 6, 11322.

90 Y. Liu, Y. Ma, Y. Jin, G. Chen and X. Zhang, J. Electroanal. Chem., 2015, 739, 172.

91 S. V. Rodil, J. I. Paredes, A. M. Alonso and J. M. D. Tascón, J. Mater. Chem., 2009, 19, 3591.

92 L. Feng, G. Gao, P. Huang, X. Wang, C. Zhang, J. Zhang, S. Guo and D. Cui, Nanoscale Res. Lett., 2011, 6, 551.

93 F. W. Low, C. W. Lai and S. B. Abd Hamid, Ceram. Int., 2015, 41, 5798.

94 Z. Ji, J. Chen, L. Huang and G. Shi, Chem. Commun., 2015, 51, 2806.

95 B. Subramanya and D. Krishna Bhat, J. Power Sources, 2015, 275, 90.

96 H. G. Xu and K. S. Suslick, J. Am. Chem. Soc., 2011, 133, 9148.

97 J. Li, F. Ye, S. Vaziri, M. Muhammed, M. C. Lemme and M. Ostling, Carbon, 2012, 50, 3092.

98 M. Lotya, P. J. King, U. Khan, S. De and J. N. Coleman, ACS Nano, 2010, 4, 3155.

99 G. S. Bang, H. M. So, M. J. Lee and C. W. Ahn, J. Mater. Chem., 2012, 22, 4806.

100 W. Liu, R. Zhou, D. Zhou, G. Ding, J. M. Soah, C. Y. Yue and X. Lu, Carbon, 2015, 83, 188. http://www.sciencedirect.com/science/article/pii/S0008622314011087.

101 M. Choucair, P. Thordarson and J. A. Stride, Nat. Nanotechnol., 2006, 4, 30.

102 B. Zhang, J. Song, G. Yang and B. Han, Chem. Sci., 2014, 5, 4656.

103 L. Wang, Q. Yao, H. Bi, F. Huang, Q. Wang and L. Chen, J. Mater. Chem. A, 2014, 2, 11107.
104 K. H. Liao, Y. S. Lin, C. W. Macosko and C. L. Haynes, Appl. Mater. Interfaces, 2011, 3, 2607.

105 A. R. Kamali and D. J. Fray, Ceram. Int., 2014, 40, 1835.

106 H. A. Laitinen, Y. Yamamura and I. Uchida, J. Electrochem. Soc., 1978, 125, 1450.

107 J. B. Raynor, Ber. Bunsen-Ges. Phys. Chem., 1963, 67, 360.

108 W. J. Burkhard and J. D. Corbett, J. Am. Chem. Soc., 1957, 79, 6361.

109 N. Q. Minh and B. J. Welch, Aust. J. Chem., 1975, 28, 965.

110 N. Q. Minh and B. J. Welch, Aust. J. Chem., 1975, 28, 2579.

111 N. Q. Minh and B. J. Welch, J. Electroanal. Chem., 1978, 92, 179.

112 J. D. Van Norman and R. J. Tivers, J. Electrochem. Soc., 1971, 118, 258.

113 Y. Sakamura, J. Electrochem. Soc., 2010, 157, E135.

114 M. H. F. Sluiter and Y. Kawazoe, Phys. Rev. B: Condens. Matter, 2003, 68, 085410.

115 W. A. Dino, Y. Miura, H. Nakanishi, H. Kasai and T. Sugimoto, J. Phys. Soc. Jpn., 2003, 72, 1867.

116 Y. Ferro, F. Marinelli and A. Allouche, Chem. Phys. Lett., 2003, 368, 609.

117 S. Casolo, O. M. Lovvik, R. Martinazzo and G. F. Tantardini, J. Chem. Phys., 2009, 130, 054704.

118 D. W. Boukhvalov, M. I. Katsnelson and A. I. Lichtenstein, Phys. Rev. B: Condens. Matter, 2008, 77, 035427.

119 C. P. Herrero and R. Ramirez, Phys. Rev. B: Condens. Matter, 2009, 79, 115429.

120 D. Voiry, H. Yamaguchi, J. Li, R. Silva, D. C. B. Alves, T. Fujita, M. Chen, T. Asefa, V. B. Shenoy, G. Eda and M. Chhowalla, Nat. Mater., 2013, 12, 850.

121 J. C. F. Boodts and S. Trasatiti, J. Appl. Electrochem., 1989, 19, 255.

122 J. Greeley, T. F. Jaramillo, J. Bonde, I. Chorkendorff and J. K. Nørskov, Nat. Mater., 2006, 5, 909.

123 B. Hinnemann, P. G. Moses, J. Bonde, K. P. Jørgensen, J. H. Nielsen, S. Horch, I. Chorkendorff and J. K. Nørskov, J. Am. Chem. Soc., 2005, 127, 5308.

124 T. F. Jaramillo, K. P. Jørgensen, J. Bonde, J. H. Nielsen, S. Horch and I. Chorkendorff, Science, 2007, 317, 100.

125 J. Bonde, P. G. Moses, T. F. Jaramillo, J. K. Nørskov and I. Chorkendorff, Faraday Discuss., 2008, 140, 219.

126 L. A. Girifalco and R. A. Lad, J. Chem. Phys., 1956, 25, 693.

127 R. Zacharia, H. Ulbricht and T. Hertel, Phys. Rev. B: Condens. Matter, 2004, 69, 155406.

128 T. Gould, S. Lebègue and J. Dobson, J. Phys.: Condens. Matter., 2013, 25, 445010.

129 R. Strobel, J. Garche, P. T. Moseley, L. Jorissen and G. Wolf, J. Power Sources, 2006, 159, 781.

130 S. Orimo, G. Majer, T. Fukunaga, A. Zuttel, L. Schlapbach and H. Fujii, Appl. Phys. Lett., 1999, 75, 3093. 